\title{
Reflecting on some of the challenges facing postgraduate nursing education in South Africa
}

\section{SUMMARY}

Considering the dearth of professional nurses in South Africa today, and the fact that postgraduate nursing education can contribute towards enhancing the competences of those in the profession, I shall examine some of the challenges faced by a group of previously enrolled postgraduate nursing students which resulted in their non-completion of a formal qualification.

The focus of this investigation was a 2008 cohort of students that did not complete their non-clinical postgraduate diplomas at the institution where I work. Of the 29 students who did not complete their studies, I have selected a group of 8 students through a purposive non-random sample with the objective to ascertain some of the reasons for them not completing their diploma. My aim was to examine some of the reasons as to why postgraduate nursing students do not complete their qualification and to suggest ways as to how the curriculum can be reconstructed as to counteract some of students' pitfalls.

Based on my qualitative interpretive analysis, I shall argue that these students did not complete their diplomas on the grounds of, having experienced a lack of institutional and social support; their inability to cope with the demands of academic rigour; their experiences of isolation and exclusion; and, the inability to cope with unimagined realities. My contention is that if postgraduate nursing is not adequately attended to, the possibility that nursing education would not contribute to the transformation of the profession, is highly possible

\section{INTRODUCTION}

Student completion and retention have not only in South Africa but also in most parts of the world become a major concern for higher education institutions. For this reason, the success of higher education institutions in South Africa is also measured against the completion (or better known as throughput) rates of students. The National Plan for Higher Education (2001) sets benchmarks for higher education institutions, indicating that the completion rates of students which entered the undergraduate and postgraduate academic programmes should be at least $75 \%$ (Bunting, 2004: 31). Successful student completion rate is also considered a priority for Stellenbosch University Nursing Division (UNEDSA proposal, SU 2009). Hence the aim of this study is to examine the underlying reasons for the non- completion of students pursuing the non-clinical postgraduate nursing diploma programmes at Stellenbosch University (SU). 


\section{Non-completion rates in postgraduate nursing education}

Internationally and in South Africa

Non-completion rates of students are one of the many similar challenges the international nursing community shares with nursing in South Africa. In the United Kingdom (UK) higher education institutions incur financial penalties if their non-completion rate is more than $13 \%$, yet recent studies (Moseley and Mead, 2008:470; Waters, 2008:12-13) have shown that non-completion rates in undergraduate programmes range from $6 \%$ to $56 \%$. A study in Japan (Horiuchi et al., 2009) which compared a face-to-face and web-based post-basic nursing group showed noncompletion rates of $31.2 \%$ and $17.8 \%$ respectively. Internationally, nursing studies refer to academic and non-academic factors, which influence completion of programmes. Academic factors encountered in the US (Porter, 2008: 3-5) that had a direct effect on student retention include: pre-admission testing, English as a second language, cultural diversity and grade point average. The non-academic factors highlighted are that of family responsibilities, internal stressors, work schedules, financial and health concerns (Ramsburg, 2007; Stewart, 2005: 8). Cooley's study (2008: 593) recommends careful consideration of nurses' motivation to study further and the impact their studies will have on their personal and work lives and also implores lecturers to offer support and facilitate solutions on how the students can overcome these barriers. Although anlrish study it is also highlighted in UK (Deary et al., 2003: 73) and US studies (Ramsburg, 2007; Stewart, 2005:8).

Very few studies on nursing attrition rates are available in South Africa and the studies that I did encounter was at an undergraduate level. Student-based reasons such as inappropriate vocation choice, poor academic performance and personal or emotional challenges were offered

\section{https://repository.uwc.ac.za}


for not completing their programme (Mashaba and Mhlongo, 1995, Wright and Maree, 2007). Wright and Maree's study exclude institutional-related factors whereas the earlier studies of Mashaba and Mhlongo (1995: 372) and Manzini (1998: 283) are more in line with international and HE South African studies and, that is, that both student and institutional supports (nature of the programme, perceived non-support from academic and non-academic staff and the learning environment) play a role in student non- completion rates. Another aspect of attrition mentioned in the South African context is that of workplace attrition. The professional registers of the South African Nursing Council (SANC) between 1997 and 2006, show a workforce attrition rate of $65 \%$ (Breier et al., 2009: 1), but this is not the focus of my study.

\section{Statement of the research problem and research objectives}

Since focusing on postgraduate programmes at Stellenbosch University Nursing Division (SUND), an annual growth rate of $20 \%-25 \%$ has been experienced, from 47 students enrolled in 2000 to 537 students enrolled in 2008 (currently there are more than 700 students in the postgraduate diploma programmes). The Interactive Telematic Education (iTE) system was implemented to accommodate the increased number of postgraduate students and to make the programmes more accessible. The completion rates for the past three years $(2005,2006$ and 2007) of the two non-clinical postgraduate diploma's (NCPGDs) are respectively $55 \%$ and $56 \%$, which comprises the majority of registered students for all diploma programmes, that is, $69.9 \%$. One of SUND's goals is to improve the pass rates of all programmes to $80 \%$ (UNEDSA proposal, SU 2009). The focus of this study is on the two NCPGD programmes that utilise iTE as a medium and the non-completion rates of the students that participate in these programmes. The study explores possible reasons related to academic and social integration and the iTE delivery mode that might influence the non-completion rates of NCPGD students.

\section{https://repository.uwc.ac.za}




\section{Research methodology}

Aim and objectives of the study

The main aim of this research study is to explore the underlying reasons as to why postgraduate nursing students do not complete their NCPGD programmes (education and management) and to investigate possible intervention strategies to improve the students' completion rates. Three specific objectives are identified and formulated as follows; firstly, to explore possible reasons related to social and academic integration that might influence the non- completion rates of NCPGD students at SUND; secondly, to explore possible reasons related to the iTE delivery mode that might influence the non-completion rates of NCPGD students; and thirdly, to explore possible intervention strategies that might enhance completion rates in NCPGD programmes.

\section{Theoretical framework}

My methodological approach in this study is interpretive as it allows you to explore people's subjective realities; in other words their feelings, value and belief systems, intentions and reasoning by interacting with them in their own worlds, trying to make sense and understand them or interpret their own words through qualitative research methods and designs (Terre Blanche et al., 2006a,b: 273). I also use Tinto's student retention theory (1975), with interpretive links, as my theoretical framework of departure. His theory holds that the more academically and socially integrated students become at institutions the better their chances are for completing.

\section{Unit of analysis}

The unit of analysis for this study is eight individual students of SUND from a population of 29 who did not complete their NCPGDs during the 2008 academic year. I choose the 2008 cohort of students because I thought the students' experiences are recent and that it would be easier for them to reflect and share the reasons as to why they did not complete their diplomas. All eight students discontinued their studies voluntarily. Five of

\section{https://repository.uwc.ac.za}


the students were registered for the postgraduate diploma in nursing management (PGDNM) and three students were registered for the postgraduate diploma in nursing education (PGDNE). Two of the eight students continued with studies in 2009; one changed her programme from PGDNE to PGDNM at SUND and the other is pursuing a psychiatric diploma through another institution. Currently the eight individuals are working in different health care facilities in the Western Cape Province.

\section{Research procedures}

The study was conducted from January 2009 until June 2009. Data generation took place through in-depth one-to-one interviews during the months of May and June.

\section{Selection of cases}

Purposive non-random sampling is used, involving information rich cases which comprises of critical (theoretically important) or typical (common or average) cases with an emphasis on the latter (Terre Blanche et al., 2006a). The participants included are based on the following decisions: they have been postgraduate diploma students of SUND that did not complete their programmes; participated in one of the non-clinical nursing programmes; were registered students for the 2008 year and were interested to participate (felt they could add value) to the research. The demographics displayed in the 2006, 2007 and 2008 cohort of students, resulted in attention also being given to gender, race, age and the specific non-clinical programme the students were registered for. Women dominate the nursing profession, but more and more males are entering the profession. For this reason I included males, but the 2008 cohort allowed for only one male to be selected as he was the only one who did not complete. The Western Cape Province differs from the other eight provinces in South Africa since it is the only province where the coloured community is in the majority, presenting more than $55 \%$ of the cohort of students. Accordingly, four coloured, two white, one black and one Indian

\section{https://repository.uwc.ac.za}


student were selected for interviews. Most of the students (19) that did not complete their diploma were between the ages 33 and 48, five were younger than 33, and five older than 48. Four students were chosen from the first age group and two respectively from the second and third age groups. Lastly, five students were selected from the PGDNM and three students from the PGDNE programme as the first group made up $65 \%$ of the cohort and the latter $35 \%$.

\section{Method of data collection}

Eight face-to-face interviews were conducted using a semi- structured interview guide. This method allows for a specific participant's experiences, feelings and opinions to be captured (Denscombe, 2003) and some flexibility in addressing the issues as it arises.

Seven open-ended questions are formulated based on my literature study and theoretical framework. Table 1 consists of the interview guide questions and their rationale.

\section{Data analysis}

As data analysis in qualitative research is a continuous process my analysis started initially with the literature review. Data analysis continued throughout the data collection period and intensified with the construction of the data. Following Creswell's (2007: 184) procedure of decoding findings are generated by an analysis of the themes or issues as it emerged during the interviews. Finally I construct a narrative of each interviewee's response through describing and analysing each participant's narrative specifically focusing on reasons that possibly contributed to the non-completion of their studies. In using narratives it allows for issues to surface in a holistic, contextual in-depth manner, but with transparency and openness.

\section{https://repository.uwc.ac.za}




\section{Ethical considerations}

In March 2008 the research proposal for this study was approved by the Committee for Master's and Doctoral Proposals at the Faculty of Education, Stellenbosch University. Ex-students from SUND participated in this study and the demographical information of the students' was obtained from institutional records for which permission was requested and granted.

\section{Informed consent and confidentiality}

The participating students who wanted to remain anonymous were willing to share their stories, which I member checked with them at a later stage of the study. Prior to the study the participants were verbally informed regarding the aims and objectives of the study and voluntarily informed consent was required. The signing of the voluntary informed consent forms took place immediately before the individual interviews and individual confidentiality was upheld through the use of unmarked interview schedules and codes. The participants were referred to by pseudonyms in the research report and in all future publications.

\section{Non-maleficence and beneficence}

Participation was voluntary and participants could withdraw or decline to participate after the commencement of the study. The study posed to be beneficial to the participants where strategies were devised in minimising them from dropping out in future studies.

\section{Findings}

Ten themes emerge from this study; six of the themes are related to student and four of the themes related to institutional factors of academic and social integration. I shall discuss the student related

\section{https://repository.uwc.ac.za}




\section{Table 1}

Questions asked during one-to-one interviews.

Academic and social integration

1. Do you work full-time or part-time?

2. What was the main motivation for you to further your studies at SUND? What was your purpose in coming to SUND?

3. What adjustments did you need to make before embarking on your studies? Which adjustments were the most difficult/strange?

4. Did SUND comply with your expectations? If NO, what did you expect and what was the reality? If YES, with what did you experience problems that led to you not completing the programme?

5. What was your experience regarding the teaching medium and the programme?

6 . How prepared/committed were you to really work hard?

7. What were the consequences for you as a person when you did not complete your studies? What did you learn from this experience?

academic and social factors first, which are; firstly, family and workplace responsibilities; secondly, inadequate knowledge of the specific programme; thirdly, inadequate preparation and or skills for postgraduate studies and resources; fourthly, unexpected circumstances (health, work, and time period between studies); fifthly, feelings of failure, disappointment, regret, stress and relief and lastly, students attitude or value system regarding their studies.

\section{Student-related factors: academic and social integration}

Family and workplace responsibilities

Since all the participants were working adults, they also had other responsibilities, for example family (which included immediate and extended family members) and workplace commitments. For three students both work (sudden change in off-duties from day to night shift, no study leave, night shift, and a busy ward) and family (chores at home, cultural responsibilities, children who felt neglected, too many assignments interfering with family and social life) played a role whereas for another

\section{https://repository.uwc.ac.za}


three students just one of the two was a factor. For two students' family and work responsibilities played no role at all.

\section{Inadequate knowledge of programmes}

Students' knowledge about what the specific programme entails was limited, for example they did not know what teaching strategy was used, the exam policies and procedures and the structure of the programme. Some students did not have any information on the programme or they received information from colleagues that were outdated. Consequently, during the programme many realised that they should have registered for a different programme. In attaining correct information many of the students could have planned their studies more effectively. Other students again had sufficient information on the programme and felt that it was the correct field for them, but yet it seems as if they are not really convinced that they should be doing it.

\section{Inadequate preparation or skills for postgraduate studies and resources}

This theme appears to be linked to the above one. Some students seem not to have the necessary competence to embark on postgraduate studies, for example not being computer literate, not knowing how to use the internet, typing skills, interpreting text and writing to values such as motivation, determination and persistence, which will be discussed in more detail under another theme.

Afrikaans-speaking students also experienced language as a challenge. The programmes are presented in English, although all assessments are offered in both Afrikaans and English. The students' also have a choice in which language they want to submit their assessments (formative and summative). For many it is the first time that they experience teaching and learning through an English medium. They also lacked resources, which ranged from not having a computer, internet and transport to at least easy access to computers, the internet and transport. This lack of resources

\section{https://repository.uwc.ac.za}


together with other challenges tremendously increased their stress levels. This brings me to the following theme where unexpected circumstances were also experienced.

\section{Unexpected circumstances (health, work and time period between studies)}

Students' faced unexpected challenges related to their health, work and the time periods between formal studies, which played a major role in them not continuing with their studies. Although one student was diagnosed in April with breast cancer, she only formally stopped her programme at the end of July, which demonstrates her strong motivation and will to persevere to complete her diploma. Another student had to unexpectedly go for training to Germany, but she persevered with her programme until mid August. To adjust to formal studies after a substantial time period elapsed also seemed to have come as unexpected for a participant who participated in formal studies twenty six years ago. Inevitably if students do not complete their studies it will have an effect on them, and these effects emerged in the next theme.

\section{Feelings of failure, disappointment, regret, stress and relief}

Although the majority of the students experienced negative feelings about not completing their programme some students felt positive about it. Some of the negative emotions experienced were that of failure, regret and disappointment. One student's feeling of relief was more than her feeling of disappointment. The stress of her studies also impacted her health. The next theme addressed students' attitudes and value system regarding their studies.

Students' attitude or value system regarding their studies

Commonalities that came to the fore in this theme were the following: students' awareness that postgraduate studies involve hard work,

$$
\text { https://repository.uwc.ac.za }
$$


dedication and making sacrifices, the importance of time management and their motivation for embarking on studies.

Most of the students' were willing to work hard and still make sacrifices. Some though felt that their social life is more important. Students' level of motivation was another aspect which seems to play a role in how hard a student is willing to work. Some students were driven by external motivation, but soon realised that that is not sufficient. Other students were driven by internal motivation. One student especially was dedicated to being a life-long learner, she started with doing the auxiliary nurse course, and then completed the enrolled nurse course, and she continued with the bridging course, completed the midwifery course and then started her postgraduate diploma in nursing management, which is the one she did not complete.

Many students' realised that proper planning and time management are very important and should be addressed by both students and lecturers. Some students' felt so strongly about this aspect that they would like lecturers to address time management during the orientation period.

\section{Institutional-related factors: academic and social integration}

\section{Lecturers' attitude or value system regarding students}

Most students felt that the lecturers' are distant, inaccessible, unapproachable and abrupt, and this seems to be the case whether students stay in the same or a different province than where the institution is situated. Although two students who had previous ties with the institution seemed to experience the exact opposite. An environment lacking in understanding, support, guidance and encouragement also came to the fore.

It thus seems that lecturers' should take into consideration that students have not been studying for some time and be more understanding and supportive throughout the programme.

\section{Presentation of the programme}

\section{https://repository.uwc.ac.za}


The issues raised under the following theme were as follows: the teaching strategy utilised, orientation to the programme, assessment strategy and the venues where the telematic broadcast took place. The interactive telematic broadcast was quite new for many students and some students seemed cautious, uncomfortable and intimidated with the telematic broadcasts sessions. Others were just happy that there was some kind of contact. As with the lecturers', feelings of distance and inapproachability were experienced. At times the telematic broadcast venues had to change due to technical hitches and caused challenges for the students who do not have transport and has to make arrangements beforehand.

A few students experienced a lack of orientation or induction to the programme, whereas others felt it was sufficient, but the lecturers could share challenges with them, which they might come across, for instance '... (tell me) what problems may I encounter, what can I expect and how can I address it?'.

One aspect about assessment mentioned was that of a technical nature. Some of the tests were done on-line and while students were busy doing the test everything would go off-line. This made them very anxious as students must complete the test in a specific time allocated and they would be unsure whether the test was saved or not. Another aspect regarding assessment was that students felt there were too many assignments, many could not type nor had the necessary resources to type on. Many of the challenges mentioned thus far could have been addressed if the students informed themselves regarding the next theme.

\section{Inadequate information available on the programme}

Students have a vague idea what the programmes entail and instead of gathering information through the correct channels they consult previous students or their colleagues. Information on the programmes is available through the university website and also a brochure. It may be that the information provided is insufficient, but students do realise that they have a responsibility in being informed about the programme they are registering

$$
\text { https://repository.uwc.ac.za }
$$


for, as one student put it very succinctly: 'With the course itself.... you must really be well- informed, comprehend what the course is about before you even apply for the course... thus you know what is expected from you...'

\section{Administrative shortcomings}

Despite raising issues such as irregular correspondence and poor communication, the one issue that generated the most discussion is that of receiving study material late. Students felt and rightfully so that their study material should reach them before they start. This students' claim prevented them from being prepared for their telematic sessions. In contrast the student that could not attend the telematic sessions and received a recording of the session afterwards appeared to have experienced more support.

The findings indicate that the students were challenged in multiple ways: a lack of opportunities to study due to work and family commitments; inadequate programme information which also resulted in indecisions about the programme of study; under- preparedness for postgraduate studies; language exclusions; unexpected challenges due to illness; feelings of blame and disappointment due to incompletion despite being motivated to complete. At the same time students' felt demotivated to complete because of institutional factors such as: inaccessible, unapproachable, abrupt lecturers (yet supportive administrative personnel); daunting, intimidating and less 'friendly' teaching approaches; and insufficient time to prepare for studies.

In essence, student completion and retention rates have been adversely affected because of institutional factors, discouragement (with reference to a value) and inappropriate teaching and learning strategies. These are the issues I wish to take up next.

\section{Limitations of infrastructural support}

My findings and the literature seem to strengthen the notion that institutional support is a necessary condition for students to succeed. This

$$
\text { https://repository.uwc.ac.za }
$$


is corroborated by Tinto's (1993) Student Integration Model (SIM) which suggests that students who strongly identify with the institution's internal characteristics will succeed, and those who do not will leave. Although the rendering of tutorial support, bursaries and student friendly study material are credible learning support structures these paraphernalia would not necessarily on their own improve the education of postgraduate students neither would these extrinsic features of education on their own bring about improved student success and retention rates. I contend that postgraduate nursing education should also be guided by intrinsic values, without which education, would fail to meaningfully exist.

I deduce that if SUND hopes to improve students' completion and retention rates it should initiate students into the values of caring and dialogism. It is to a discussion on these conditions of postgraduate nursing education which I now turn my attention.

\section{Values initiation}

Most if not all of the participants mention the value of perseverance as crucial to succeed in their studies. By perseverance they mean that the lecturers ought to be more supportive and patient towards them during the course of the programme. It seems as if the students regard perseverance as a two-directional process, that is, lecturers should be patient with students, and the latter ought to be patient towards lecturers. One requires such a process which involves a mutual concern for one another. Hence I would extend perseverance to caring because the latter implies exercising some form of patience towards and concern for the other.

Noddings (1992: 24) in reference to nursing education considers caring as 'a moment in which each (lecturer and student) must decide how to meet the other and what to do with the moment... a moment of receptivity - one in which the full humanity of both parties is recognised - and it is followed by a return to the human other in all his or her fullness'. I am thus advocating that university lecturers (like me) involved in the education of postgraduate students ought to take more care (which also involves a form of perseverance) in initiating students into their learning. This means

\section{https://repository.uwc.ac.za}


besides students' being motivated, committed and agreeable, lecturers should also initiate students' into the discourse of learning, thus recognising their 'full humanity' which in turn is followed by a process of evoking their potentialities. In turn, students then become deeply committed to their studies and the completion thereof.

Hence, SUND should be a division within the university whose purpose is to care for students and develop both lecturers and students to care; to create a feeling of community that cares; and to develop respect for a range of human capacities. I am reminded by Tinto's (1993) argument in which he claims that the capacity of higher education institutions to bond students collaboratively and caringly is important to not only their integration in institutions but also their retention and completion.

\section{Dialogical teaching and learning pedagogy}

The findings suggest that student retention and completion rates can be enhanced through dialogical teaching and learning. The most important function which dialogical action performs is that of communication. Young (2000: 23) promotes communication as a condition for dialogical action that 'promotes free and equal opportunity to speak. (where none of the participants) is in a position to coerce or threaten others into accepting certain proposal or outcomes'.

Considering Young's ideas on communication, the implications for teaching and learning would be as follows: one has to be willing and open to listen to the views of others; to be persuaded or influenced by others' views which make sense; to take others' views into questioning; and to modify, adapt or even abandon inappropriate or incorrect views. If these practices happen, communication occurs and teaching and learning would hopefully be a dialogical encounter.

\section{Limitations of the study}

The interpretive paradigm in which this study is situated, lends itself to the following limitations:

\section{https://repository.uwc.ac.za}


Firstly, in qualitative research there is always a concern of potential researcher bias where the researcher may have interpreted the data according to her own perceptions rather than the perceptions of the participants'.

Secondly, since my design has been guided by interpretivism there seems to be little pedagogical space to change the situation of non-completion rates of the students. Consequently an action research approach would have been apposite here, on the grounds that some form of corrective strategy could have been utilised to address a distorted situation. As it stands, interpretvism merely offers one an opportunity to ascertain the constitutive reasons of a lack of completion rates.

Thirdly, the study was conducted with one group of students who did not complete their studies in the same year. Preferably it should be repeated with other groups of students in different years at the same institution or at another similar institution, which might hopefully render more justifiable results in varying or multifaceted institutional contexts.

Without dismissing the afore-mentioned weaknesses of the study, I am persuaded by the positive contributions caring and dialogism can render to enhance student completion rates - an aspect which the literature does not always accentuate.

In the main, student non-completion rates has a better chance of being improved or even remedied if nurse educators could attend more convincingly to the notions of caring and dialogical engagement with students. This implies that nurse educators would potentially create opportunities to evoke students' potentialities (that is, to care); and equally important to become more engaging with students whereby they become situated in the lived experiences of students.

\section{References}


Breier, M., Wildschut, A., Mgqolozana, T., 2009. Nursing in a New Era: The Profession and the Education of Nurses in South Africa. HSRC Press, Cape Town.

Bunting, I., 2004. Student retention: a macro perspective from South Africa. In: Yorke, M., Longden, B. (Eds.), Retention and Student Success in Higher Education. Open University Press, Berkshire, pp. 16-31.

Cooley, M.C., 2008. Nurses' motivations for studying third level post-registration nursing programmes and the effects of studying on their personal and work lives. Nurse Education Today 28, 588-594.

Creswell, J., 2007. Qualitative Inquiry and Research Design: Choosing Among Five Approaches. Sage, Thousand Oaks.

Deary, I., Watson, R., Hogston, R., 2003. A longitudinal cohort study of burnout and attrition in nursing students. Journal of Advanced Nursing 43 (1), $71-81$.

Denscombe, M., 2003. The Good Research Guide: for small-scale social research projects. Open University Press, Philadelphia, USA.

Horiuchi, S., Yukari, Y., Koyo, M., Sakyo, Y., Nakayama, K., 2009. Evaluation of a web-based graduate continuing nursing education program in Japan: a randomised controlled trial. Nurse Education Today 29 (1), 140-149.

Manzini, H. 1998. Student nurses drop out. Unpublished D Litt et Phil thesis. (Pretoria: University of South Africa).

Mashaba, G., Mhlongo, T., 1995. Student nurse wastage: a case study of the profile and perceptions of students of an institution. Journal of Advanced Nursing 22 (1), 364-373.

Moseley, L., Mead, D., 2008. Predicting who will drop out of nursing courses: a machine learning exercise. Nursing Education Today 28 (1), 469-475.

Noddings, N., 1992. The Challenge to Care in Schools: An Alternative Approach to Education. Teachers College Press, New York \& London.

Porter, K., 2008. Current trends in student retention: a literature review. Teaching and Learning in Nursing 3 (1), 3-5.

\section{https://repository.uwc.ac.za}


Ramsburg, L., 2007. Strive for success: a successful retention program for Associate of Science in nursing students. Teaching and Learning in Nursing 2 (1), 12-16.

Stewart, B., 2005. Enhancing success in BSN Nursing Education for minority nurses. The ABNF Journal 1 (1), 8-10.

Terre Blanche, M., Durrheim, K., Painter, D., 2006a. Research in Practice: Applied Methods for the Social Sciences. UCT Press, Cape Town.

Terre Blanche, M., Kelly, K., Durrheim, K., 2006b. Why qualitative research? In: Terre Blanche, M., Durrheim, K., Painter, D. (Eds.), 2006 Research in Practice: Applied Methods for the Social Sciences. UCT Press, Cape Town, pp. 271-284. Tinto, V., 1975. Dropout from higher education: a theoretical synthesis of recent

research. Review of Educational Research 45 (1), 89-125. Tinto, V., 1993. Leaving College: Rethinking the Causes and Cures of Student Attrition, Second Edition. University of Chicago Press, Chicago.

UNEDSA, 2009. Stellenbosch University Nursing Division SEEDS Proposal: Transforming Nursing Leadership through Innovative Postgraduate Education and Research. Stellenbosch University, Tygerberg. Waters, A., 2008. Nursing attrition is. Nursing Standard 22 (31), 12-15. Wright, S., Maree, J., 2007. First year Baccalaureate nursing students: reasons for drop-out? South African Journal of Higher Education 21 (5), 596-609. 